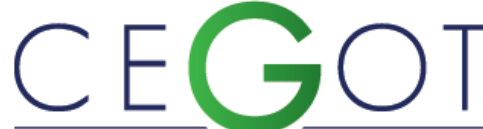

Centro de Estudos de Geografia e Ordenamento do Território
RIBEIRO, CRISTIENE

Universidade do Estado do Rio de Janeiro, Instituto de Geografia /Departamento de Geografia Humana

Rua São Francisco Xavier, 524, 4ํandar, sala 4023, Bloco B Maracanã, Rio de Janeiro/ RJ - 20550-013 - Brasil

Cristiene cnr@hotmail.com

\title{
A espacialização da distribuição dos serviços e suporte para bicicletas no município do Rio de Janeiro
}

The "spatialization" of the distribution of bicycles services and support in the city of Rio de Janeiro

Referência: Ribeiro, Cristiene (2018). A espacialização da distribuição dos serviços e suporte para bicicletas no município do Rio de Janeiro. Revista de Geografia e Ordenamento do Território (GOT), n. ${ }^{\circ} 13$ (junho). Centro de Estudos de Geografia e Ordenamento do Território, p. 389-407, dx.doi.org/10.17127/got/2018.13.017

\section{RESUMO}

Pretende-se, com esse artigo, acrescentar à reflexão que já é realizada por alguns autores sobre o fenômeno da exclusão social-espacial, introduzindo, para isso, o caso da distribuição espacial das bicicletas compartilhadas, ciclovias, bicicletários e serviços de suporte aos indivíduos que utilizam a bicicleta como transporte ou lazer no município do Rio de Janeiro. Partindo da premissa que para o Estado todos os indivíduos possuem os mesmos direitos e deveres, mas que empiricamente as políticas públicas para a mobilidade por bicicleta no município do Rio de Janeiro seguem o modelo dicotômico, onde as áreas mais nobres são privilegiadas em detrimentos das demais.

Palavras-chave: Mobilidade urbana, bicicleta, exclusão sócio espacial.

\section{ABSTRACT}

It is intended, with this article, to add to the reflection already made by some authors on the phenomenon of social-spatial exclusion, introducing, for this, the case of spatial distribution of shared bicycles, bicycle lanes and bicycle lifts, supportive services for individuals who use the bicycle as transportation or leisure in the municipality of Rio de Janeiro. Starting from the premise that for the State all individuals have the same rights and duties, but that empirically the public policies for mobility by bicycle in the city of Rio de Janeiro follow the dichotomous model, where the noblest areas are privileged at the detriment of others. 
Keywords: Urban mobility, cycling, socio-spatial exclusion.

\section{Introdução}

A redução das disparidades sociais é um grande desafio para a sociedade contemporânea, o acesso aos meios de transporte, saúde, educação, esportes, lazer etc. está diretamente ligado à qualidade de vida do indivíduo e de sua família. Contudo, alguns governos não tratam esse tema com a devida importância, seja por falta de verbas ou por falta de direcionamento político, alocando, assim, os bens e serviços públicos em áreas nobres que historicamente concentram recursos, enquanto parte da população ainda se encontra excluída.

O Estado brasileiro a partir de 1950, como planejador e produtor do espaço público, não isento de ideologia, investiu nas mudanças das grandes cidades capitalistas, especialmente em ruas, estradas e vias expressas que beneficiam, sobretudo, os que se locomovem com automóvel particular, de sua casa para o trabalho, trabalho para o shopping, sem viver a cidade fora de suas caixas, segundo o conceito de Henri Lefebvre 1961. De acordo com Lefebvre (1961, p. 111), "no trânsito automobilístico, as pessoas e as coisas se acumulam, se misturam sem se encontrar. É o caso surpreendente de simultaneidade sem troca, ficando cada elemento na sua caixa, cada um bem fechado na sua carapaça". As vias urbanas que outrora foram construídas para a fluidez dos carros tornam-se entupidas, inchadas, não são mais capazes de suportar a quantidade de veículos que ali circulam diariamente. Por isso, a discussão sobre mobilidade urbana é tão cara para os moradores e pesquisadores de grandes cidades, portanto, precisa transcender o paradigma rodoviarista motorizado e contemplar diferentes meios de transporte que incluam todas as áreas da cidade independente do rendimento da população.

No Brasil, a região metropolitana (RM) mais crítica em relação às horas gastas na locomoção trabalho X casa é a RM do Rio de Janeiro. A região metropolitana de São Paulo ficou em segundo lugar no ranking realizado pela Federação das Indústrias do Estado do Rio de Janeiro (FIRJAN), uma associação privada sem fins lucrativos, com o objetivo de promover a competitividade empresarial, educação e qualidade de vida para a sociedade e os 
trabalhadores da indústria, contribuindo assim para o desenvolvimento sustentável do Estado do Rio de Janeiro O ranking foi realizado e apresentado pela FIRJAN em 2015, a partir da comparação do tempo de deslocamento trabalho $x$ casa de 37 regiões metropolitanas brasileiras em 2011 e 2012, a RM do Rio de Janeiro ocupa o primeiro lugar com 2,8 milhões de trabalhadores que perdem, em média, 2 horas e vinte minutos por dia para ir e voltar do trabalho. Essa situação é um reflexo do modelo rodoviarista de mobilidade escolhido no Brasil que imprime marcas significativas no espaço e, por consequência, na vida dos cidadãos.

A partir desse colapso, alguns meios de transportes alternativos começam a popularizar-se no Rio de Janeiro, como: Metrô na superfície (ônibus comum com as cores do Metrô-Rio), Bus Rapid Transit (BRT), Moto-taxi, todos insistindo no modelo rodoviarista motorizado que é refém das grandes indústrias de petróleo, construção civil e automobilística, cuja ampliação se assomava ao projeto de construção de estradas. A esse respeito, as bicicletas são excetuadas no projeto do modelo rodoviarista, ainda que se revelem inúmeros aspectos a serem elencados que as tornam uma alternativa urbana. Tratando-se do único modal de transporte excetuado do sistema rodoviário motorizado, ele independe de energia não renovável, funciona como um alimentador das redes de transporte de massa, sendo mais barato, tanto em relação à produção quanto à manutenção, cuja média de velocidade pode ser maior que a de um carro durante o horário de pico e ocupa um espaço menor que o do automóvel, além de não apresentar ruídos. Por isso, novamente, as bicicletas estão sendo vistas pela população, órgãos públicos e privados como meio de transporte para aumentar a mobilidade urbana.

Com discussões sobre cidades sustentáveis, economia verde, redução da emissão de gases poluentes, cidades mais humanas somadas às vantagens da bicicleta, há alguns anos, o governo do município do Rio de Janeiro começou a investir no suporte e na promoção do modal de transporte que esta em franco crescimento no Rio de Janeiro e no mundo, a bicicleta.

Por meio de pesquisa sobre a distribuição espacial das estações de bicicletas compartilhadas, da rede cicloviária e dos bicicletários, é possível compreender as práticas do governo municipal e, até mesmo, compará-las com o discurso, embutidas no plano de mobilidade urbana. A avaliação da espacialização dos recursos públicos e privados pode 
constituir um alerta para uma mudança de postura dos governos municipais, permitindo a visualização dos efeitos das más distribuições de recursos e, assim, se conscientizar da responsabilidade do poder público sobre a perpetuação ou a minimização da segregação sócio-espacial das cidades, segundo discorre Melissa Apassamani Boni.

As abordagens qualitativas e quantitativas utilizadas ao longo do trabalho serão norteadas pelos seguintes objetivos específicos:

- Analisar, por meio de revisão bibliográfica, os investimentos públicos voltados para o uso da bicicleta como modal de transporte, a desigual distribuição dos serviços de bicicletas compartilhadas no município do Rio de Janeiro;

- Identificar a desigualdade sócio-espacial na cidade por meio do serviço de bicicletas.

A pesquisa empírica se consistiu a partir do registro e da análise da distribuição espacial urbana dos grupos sociais e dos recursos públicos voltados para o modal de bicicleta. Assim, a partir de informações do Armazém de Dados, do Diário Oficial da Prefeitura Municipal do Rio de Janeiro, foi realizado um mapa retratando a sincronia entre a disponibilidade do serviço para bicicletas e o elevado Índice de Desenvolvimento Humano-IDH da população local, com base em indicadores municipais e georreferenciados, visando obter uma leitura espacial da situação de desigualdade urbana. Em seguida, por falta de dados mais recentes, partiu-se para uma etapa de levantamento dos recursos públicos investidos no período entre 1990 e 2011, por meio da análise das publicações oficiais e outros relatórios, serão apresentados às abordagens teóricas e empíricas sobre a dinâmica da desigualdade social imbricada no processo de segregação sócio-espacial.

\section{Rio de Janeiro: um município desigual nos investimentos em mobilidade urbana por bicicleta}

O município do Rio de Janeiro, capital do estado com o mesmo nome, está localizado na região sudeste do Brasil, entre o estado de São Paulo, Espírito Santo e Minas Gerais, e possui toda sua costa virada para o Oceano Atlântico e uma porção de terra de aproximadamente $1200 \mathrm{~km}^{2}$, além de cerca de seis milhões e trezentos e vinte mil pessoas 
habitando nesse território, mais ou menos metade da população da região metropolitana do estado do Rio de Janeiro - RMRJ. Considerando a taxa de urbanização que consiste na proporção da população residente em áreas urbanas a RMRJ é a segunda mais urbanizada do Brasil, atrás apenas de São Paulo, de acordo com o IBGE-Instituto Brasileiro de Geografia e Estatística 2010. O PIB per capita carioca (gentílico) é o segundo maior do Brasil, o qual antecede apenas de São Paulo.

O município é dividido em cinco áreas de planejamento urbano (Cf. Mapa 1), estabelecidas a partir do zoneamento do território municipal segundo critérios de compartimentação ambiental, de características histórico-geográficas e de uso e ocupação do solo. As cinco áreas de planejamento englobam as dezesseis regiões de planejamento, que são compartimentadas seguindo critérios de homogeneidade específica, aspirando à organização das informações e a agregação das ações descentralizadas dos órgãos municipais na aplicação de políticas públicas setoriais.

\section{Áreas de Planejamento e bairros do município do Rio de Janeiro}

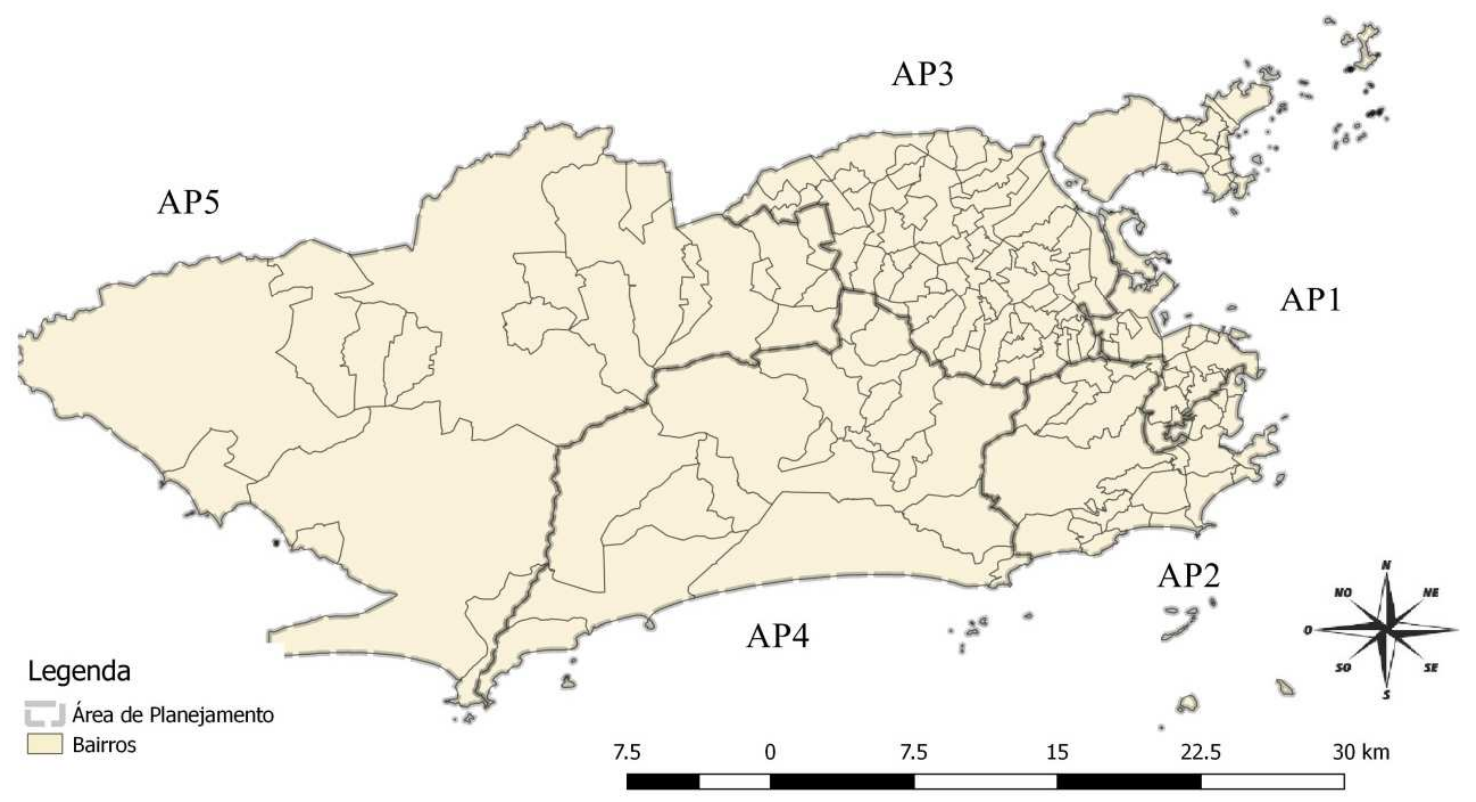

Mapa 1 - Áreas de planejamento e bairros do Rio de Janeiro Elaboração própria, 2017. 
O município do Rio de Janeiro concentra altos números, tanto do ponto de vista demográfico, como do ponto de vista dos serviços públicos e privados. Nesse contexto, acomoda a sede de grandes empresas de escala estadual e nacional, configurando uma cidade muito dinâmica, que engloba serviços especializados de relevância nacional.

Contudo, mesmo com tamanha importância, a capital fluminense constitui um espaço marcado por exacerbadas disparidades e contradições sociais notórias pela distribuição desigual dos serviços e equipamentos públicos e privados. A análise da distribuição de renda per capita revela considerável concentração de renda, onde os mais ricos e moradores dos bairros mais nobres acumulam boa parte do capital financeiro, enquanto uma pequena parcela da riqueza é distribuída entre a maior parte da população. Ou seja, a estrutura social se retraduz no espaço físico, especialmente em contextos metropolitanos e, por isso, tornase fundamental analisar a espacialização dos serviços públicos nas cidades.

Nesse trabalho, será discutida a desigualdade em relação aos investimentos no transporte cicloviário no Rio de Janeiro. Partimos do pressuposto de que todos os cidadãos são iguais perante o Estado, ou seja, todos os indivíduos e comunidades têm direito ao mesmo tratamento perante o Estado. A igualdade é garantida constitucionalmente e é fundamental para a formação de um cidadão pleno de direitos e deveres. A seguir, tal afirmação é endossada, com o respaldo da constituição da república federativa do Brasil, de 1988:

TíTULOII

Dos Direitos e Garantias Fundamentais

Art. 50 Todos são iguais perante a lei, sem distinção de qualquer natureza, garantindo-se aos brasileiros e aos estrangeiros residentes no País a inviolabilidade do direito à vida, à liberdade, à igualdade, à segurança e à propriedade, nos termos seguintes. Art. 60 São direitos sociais a educação, a saúde, a alimentação, o trabalho, a moradia, o transporte, o lazer, a segurança, a previdência social, a proteção à maternidade e à infância, a assistência aos desamparados, na forma desta Constituição. (Constituição Federal do Brasil, 1988)

Como será mostrado nos próximos parágrafos, há grupos que não são contemplados pelos direitos fundamentais, tal qual relata a constituição de 1988. Os grupos não atendidos pelas políticas públicas são privados de direitos, privados da mobilidade urbana, de transporte, e não são vistos pelo poder público como iguais a outros determinados grupos. De tal modo, não têm seu status de cidadão reconhecido, ficando à margem das políticas públicas e, 
assim, de parte da sociedade. A seguir, um trecho do artigo Concepções de igualdade $e$ cidadania (OLIVEIRA, 2011, p. 38), que corrobora a afirmação postulada.

O status igualitário passa a ser um forte símbolo de equanimidade nas relações sociais e um parâmetro importante para a avaliação das instituições de justiça, sendo a desigualdade, no plano da cidadania, percebida como uma negação da dignidade daquele que não tem o seu status igualitário reconhecido.

O município do Rio de Janeiro é um dos mais urbanizados do Brasil, e é também um dos mais desiguais de acordo com o índice (ou coeficiente) de Gine, que é um instrumento para medir o grau de concentração de renda em determinado grupo, cidade etc. Além do índice de Gine, a disparidade social é perceptível espacialmente no município do Rio de Janeiro, que também pode ser avaliada pela ausência ou presença de políticas de mobilidade urbana nas diversas áreas.

A ausência de alguns serviços públicos nas áreas suburbanas é nítida, serviços esses fundamentais para o consumo produtivolcoletivo, que viabilizam a força de trabalho e a qualidade de vida. Poderíamos citar a quantidade de hospitais, escolas de excelência, policiamento, teatros, cinemas etc, mas o trabalho vai limitar-se a mobilidade urbana ou a falta dela.

Conforme tratamos anteriormente, a capital fluminense é dividida em áreas de planejamento, especificamente cinco áreas de planejamento urbano, veja a Tabela 1, estabelecidas pelo fracionamento do território municipal a partir de critérios de compartimentação ambiental, de características histórico-geográficas e de uso e ocupação do solo. As áreas de planejamento englobam as dezesseis regiões de planejamento, que são compartimentadas seguindo critérios de homogeneidade específica, aspirando à organização das informações e a agregação das ações descentralizadas dos órgãos municipais na aplicação de políticas públicas setoriais, de acordo com a lei complementar de número 111 de $1^{\circ}$ de fevereiro de 2011, que institui o Plano Diretor de Desenvolvimento Urbano Sustentável do Município do Rio de Janeiro, o qual tem o intuito de abordar a política urbana e ambiental do município. No quadro abaixo estão exemplificadas as APs e RPs. 


\begin{tabular}{|c|c|c|c|c|}
\hline \multicolumn{5}{|c|}{ ÁREAS DE PLANEJAMENTO E REGIÕES DE PLANEJAMENTO } \\
\hline $\begin{array}{c}\text { Área de } \\
\text { planejamento } 1\end{array}$ & $\begin{array}{c}\text { Área de } \\
\text { planejamento } 2\end{array}$ & $\begin{array}{c}\text { Área de } \\
\text { planejamento } 3\end{array}$ & $\begin{array}{c}\text { Área de } \\
\text { planejamento } 4\end{array}$ & $\begin{array}{c}\text { Área de } \\
\text { planejamento } 5\end{array}$ \\
\hline \multirow[t]{7}{*}{$\begin{array}{c}\text { Região de } \\
\text { Planejamento } 1.1 \\
\text { - Centro }\end{array}$} & $\begin{array}{c}\text { Região de } \\
\text { Planejamento } 2.1 \\
\text { - Zona Sul }\end{array}$ & $\begin{array}{c}\text { Região de } \\
\text { Planejamento } 3.1 \\
\text { - Ramos }\end{array}$ & $\begin{array}{c}\text { Região de } \\
\text { Planejamento } 4.1 \\
\text { - Jacarepaguá }\end{array}$ & $\begin{array}{c}\text { Região de } \\
\text { Planejamento } 5.1 \\
\text { - Bangu }\end{array}$ \\
\hline & $\begin{array}{c}\text { Região de } \\
\text { Planejamento } 2.2 \\
\text { - Tijuca }\end{array}$ & $\begin{array}{c}\text { Região de } \\
\text { Planejamento } 3.2 \\
\text { - Méier }\end{array}$ & $\begin{array}{c}\text { Região de } \\
\text { Planejamento } 4.2 \\
\text { - Barra da Tijuca }\end{array}$ & $\begin{array}{c}\text { Região de } \\
\text { Planejamento 5.2 } \\
\text { - Campo Grande }\end{array}$ \\
\hline & & $\begin{array}{c}\text { Região de } \\
\text { Planejamento } 3.3 \\
\text { - Madureira }\end{array}$ & & $\begin{array}{c}\text { Região de } \\
\text { Planejamento 5.3 } \\
\text { - Santa Cruz }\end{array}$ \\
\hline & & $\begin{array}{c}\text { Região de } \\
\text { Planejamento } 3.4 \\
\text { - Inhaúma }\end{array}$ & & $\begin{array}{c}\text { Região de } \\
\text { Planejamento } 5.4 \\
\text { - Guaratiba }\end{array}$ \\
\hline & & $\begin{array}{c}\text { Região de } \\
\text { Planejamento } 3.5 \\
\text { - Penha }\end{array}$ & & \\
\hline & & $\begin{array}{c}\text { Região de } \\
\text { Planejamento } 3.6 \\
\text { - Pavuna }\end{array}$ & & \\
\hline & & $\begin{array}{c}\text { Região de } \\
\text { Planejamento } 3.7 \\
\text { - Ilha do } \\
\text { Governador }\end{array}$ & & \\
\hline
\end{tabular}

Tabela 1 - Áreas de Planejamento e Regiões de Planejamento.

Fonte: Armazém de dados, 2010.

Com a tabela 1 é possível averiguar uma concentração na distribuição de regiões de planejamento, pois há uma grande quantidade de RPs na área de planejamento 3 que engloba grande parte da zona norte carioca. A região de planejamento 3 é a que acomoda o maior quantitativo populacional, $38 \%$ de toda população carioca de acordo com a prefeitura do Rio de Janeiro, mesmo não sendo a que tem o maior território total (Cf. Gráfico 1). Segue abaixo um gráfico e uma tabela sobre a população total por áreas de planejamento (Tabela 2). 


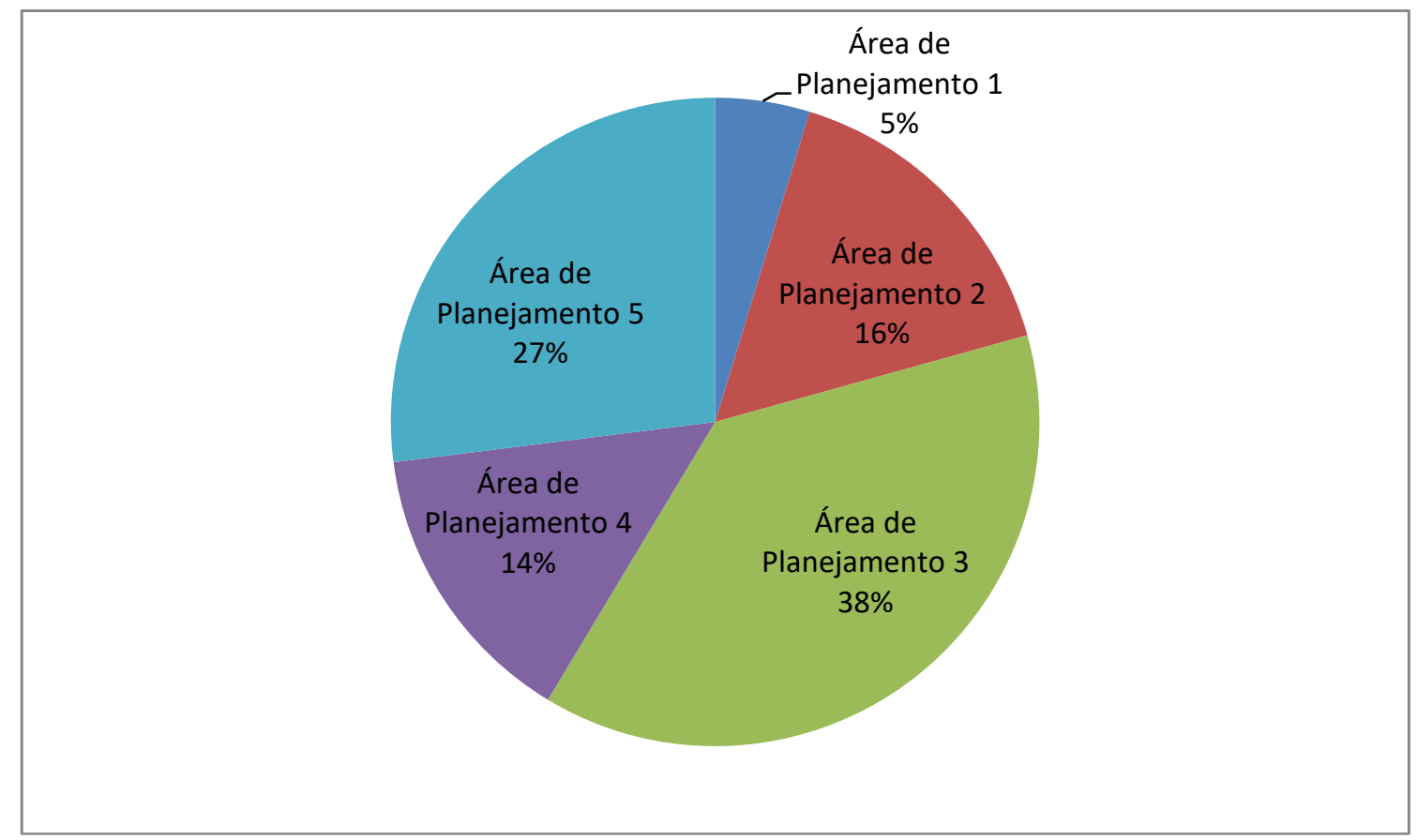

Gráfico 1 - População total por áreas de planejamento Fonte: Armazém de dados, 2010.

\begin{tabular}{|l|l|l|}
\hline Áreas de Planejamento e & $\begin{array}{l}\text { População } \\
\text { Regiões Administrativas } \\
\text { residente }\end{array}$ & $\begin{array}{l}\text { Média de moradores em domicílios } \\
\text { particulares ocupados }\end{array}$ \\
\hline Total & 6320446 & 2,94 \\
\hline Área de Planejamento 1 & 297976 & 2,84 \\
\hline Área de Planejamento 2 & 1009170 & 2,50 \\
\hline Área de Planejamento 3 & 2398572 & 3,03 \\
\hline Área de Planejamento 4 & 909955 & 2,94 \\
\hline Área de Planejamento 5 & 1704773 & 3,19 \\
\hline
\end{tabular}

Tabela 2 - População total por área de Planejamento Fonte: Armazém de dados, 2010. 
Mesmo sendo a área que acomoda $38 \%$ de toda a população da cidade, a região administrativa mais densa populosamente em relação à população por $\mathrm{km}^{2}$ é a segunda área que menos recebeu recursos para o transporte cicloviário, como será mostrado no gráfico mais adiante, ficando atrás apenas da área de planejamento um (centro) que é a menor área em relação ao território e à população residente. As informações sobre a quantidade da população e a divisão de regiões de planejamento urbano mostram como a cidade é organizada assimetricamente, pois, como se percebe, há áreas que os recursos públicos para mobilidade por bicicleta não alcançam ou são insuficientes, geralmente áreas com os menores índices de desenvolvimento social.

A Secretaria Municipal de Meio Ambiente - SMAC que foi criada após a ECO92 afirma a importância do desenvolvimento sustentável trançando políticas ambientais para a cidade. Assim, os investimentos em novos meios de transporte receberam mais atenção do governo municipal, transformando a percepção da bicicleta, vista única e exclusivamente para o lazer, para um modal de transporte que não produz gases poluentes, medida que futuramente trará benefícios para a qualidade do ar, do trânsito e da vida dos cidadãos.

O gráfico abaixo demonstra o investimento em estrutura cicloviária, bem como a distribuição espacial por região de planejamento na cidade do Rio de Janeiro. O cálculo é feito por quilômetros, desde 1990 até 2011 (Cf. Gráfico 2) e elucida a assimetria dos investimentos da prefeitura por área de planejamento.

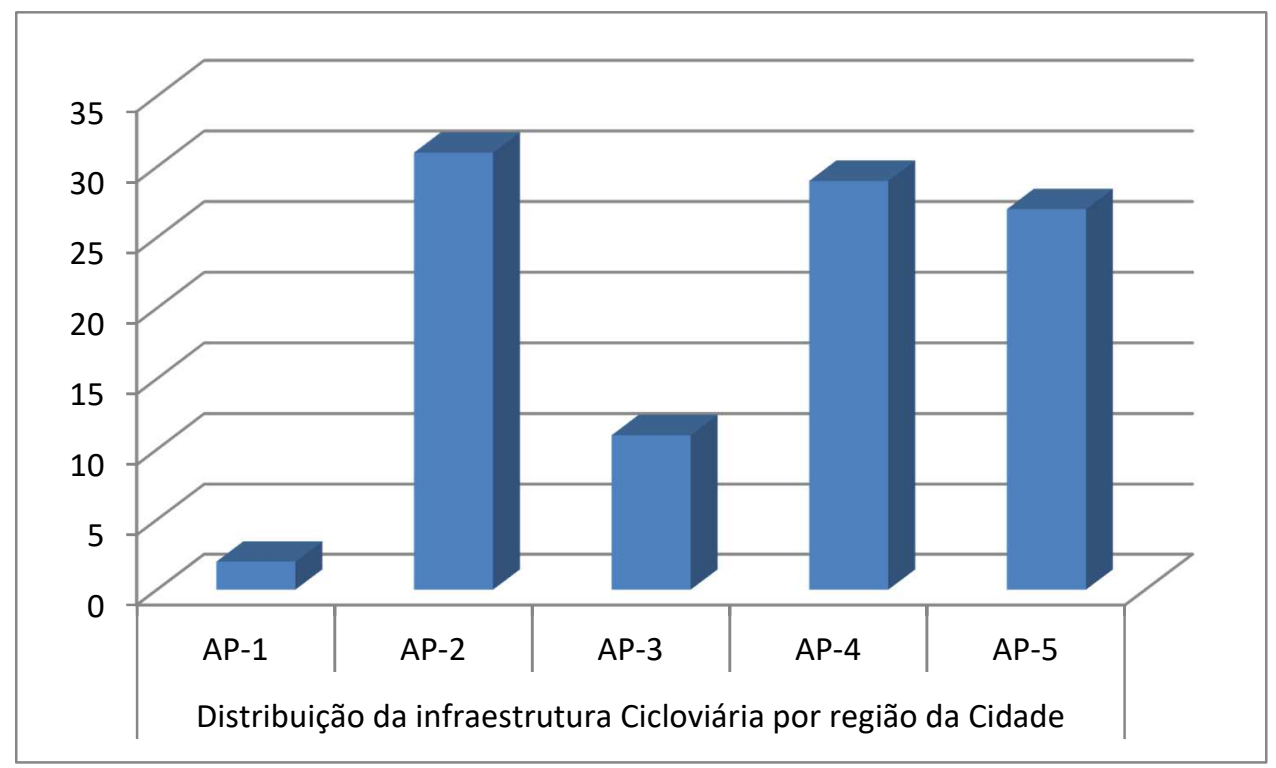

Gráfico 2 - Extensão (KM) da malha cicloviária no Rio de Janeiro em 2011 Fonte: Armazém de dados, 2011. 
Após alguns anos de investimento em um novo modal de transporte, a disparidade dos investimentos públicos permanece. A AP3, que continua sendo a mais populosa, conforme mostrado na tabela dois (População total por área de Planejamento), é a que menos recebe investimentos em transporte por bicicleta proporcionalmente, o que pode ser verificado no gráfico dois.

Apesar das afirmações colhidas na bibliografia de que os cidadãos não devem ser distinguidos de acordo com sua renda, cor, religião, ou quaisquer outros fatores, pode-se perceber que a prática dos investimentos em transporte cicloviário no município do Rio de Janeiro não leva tais declarações em consideração. A seguir, tem-se um gráfico sobre o rendimento médio mensal dos moradores divididos por áreas de planejamento. Podemos perceber que há uma disparidade no rendimento mensal de acordo com as áreas de planejamento, e essas seguem os investimentos públicos para novo modal que o Rio de Janeiro incorporou. Torna-se claro que os locais que mais receberam capital púbico são as áreas em que o rendimento médio mensal é maior. Grande exemplo disso é a área de planejamento número dois (AP2), correspondente à zona sul, cujo valor do metro quadrado é o mais caro do município, onde são localizadas as praias mais famosas e as lojas mais caras do Rio de Janeiro (Cf. Gráfico 3).

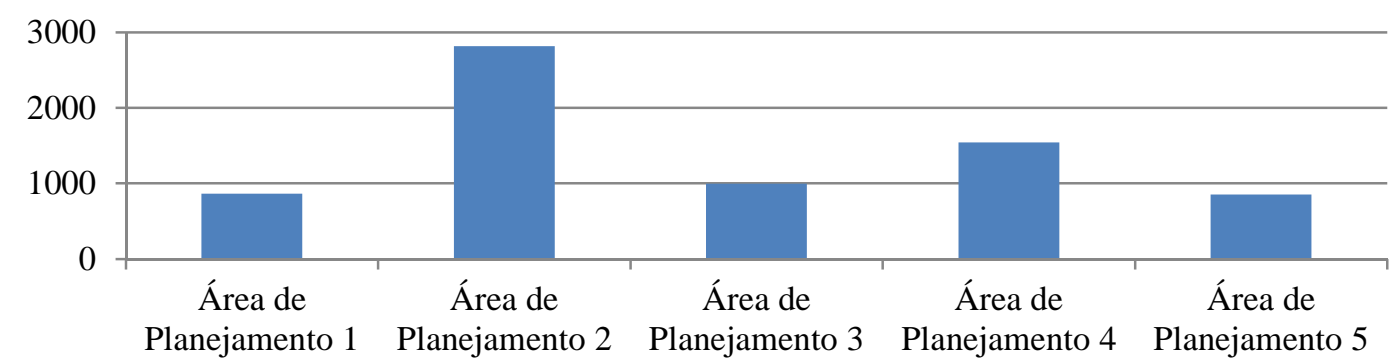

Gráfico 3 - Rendimento médio Mensal por áreas de planejamento Fonte: Armazém de dados, 2010. 


\section{- Estações de Bicicletas \\ - Rede Cicloviária \\ Regiões de Planejamento



Legenda



22.5

$30 \mathrm{~km}$

Mapa 2 - Rede cicloviária e bicicletas compartilhadas por regiões de planejamento do município do Rio de Janeiro.

Elaboração própria, 2017.

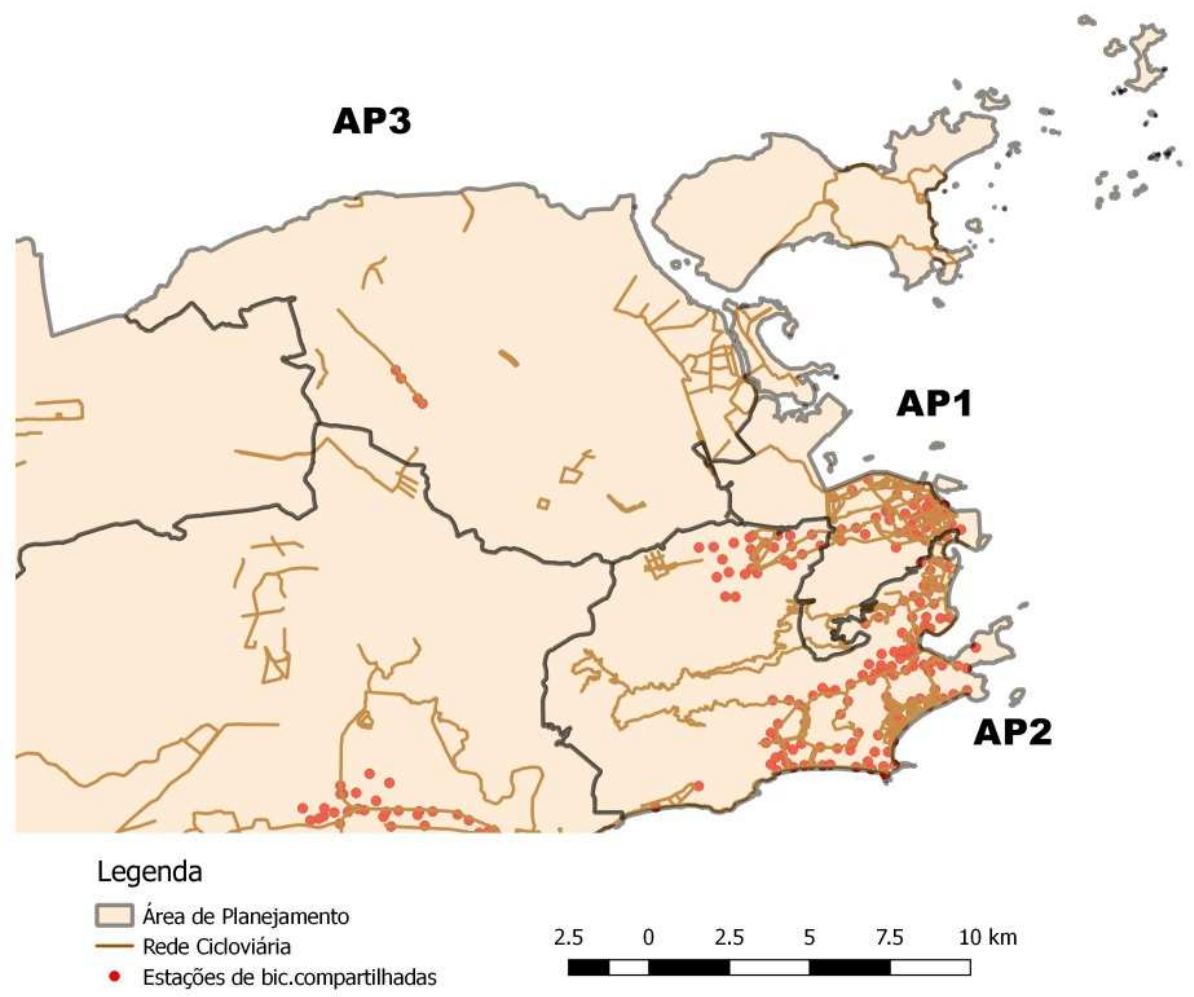

Mapa 3 - Rede cicloviária e bicicletas compartilhadas nas áreas de planejamento 1, 2 e 3 do município do Rio de Janeiro.

Elaboração própria, 2017. 


\section{Legenda}

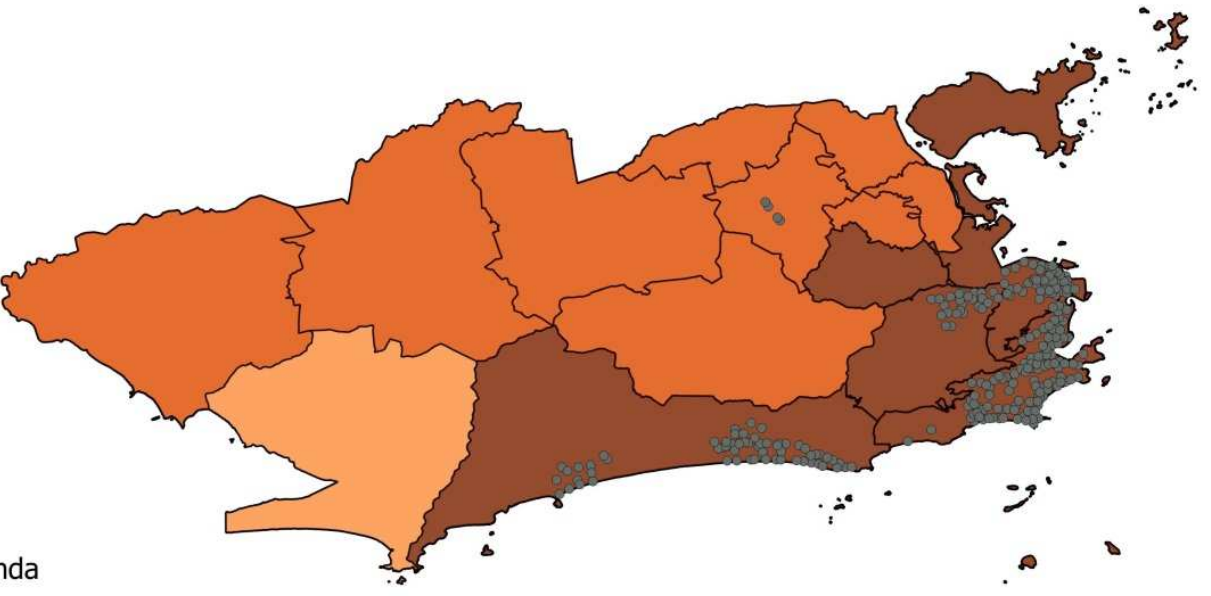

- Estações de bicicletas - Bike Rio

Índice de desenvolvimento social

$493.0000-538.8000$

$538.8000-584.6000$

$584.6000-630.4000$

$630.4000-676.2000$

$676.2000-722.0000$

Regiões de Planejamento


Mapa 4 - Bicicletas compartilhadas por regiões de planejamento do município do Rio de Janeiro e índice de desenvolvimento social

Elaboração própria, 2017.

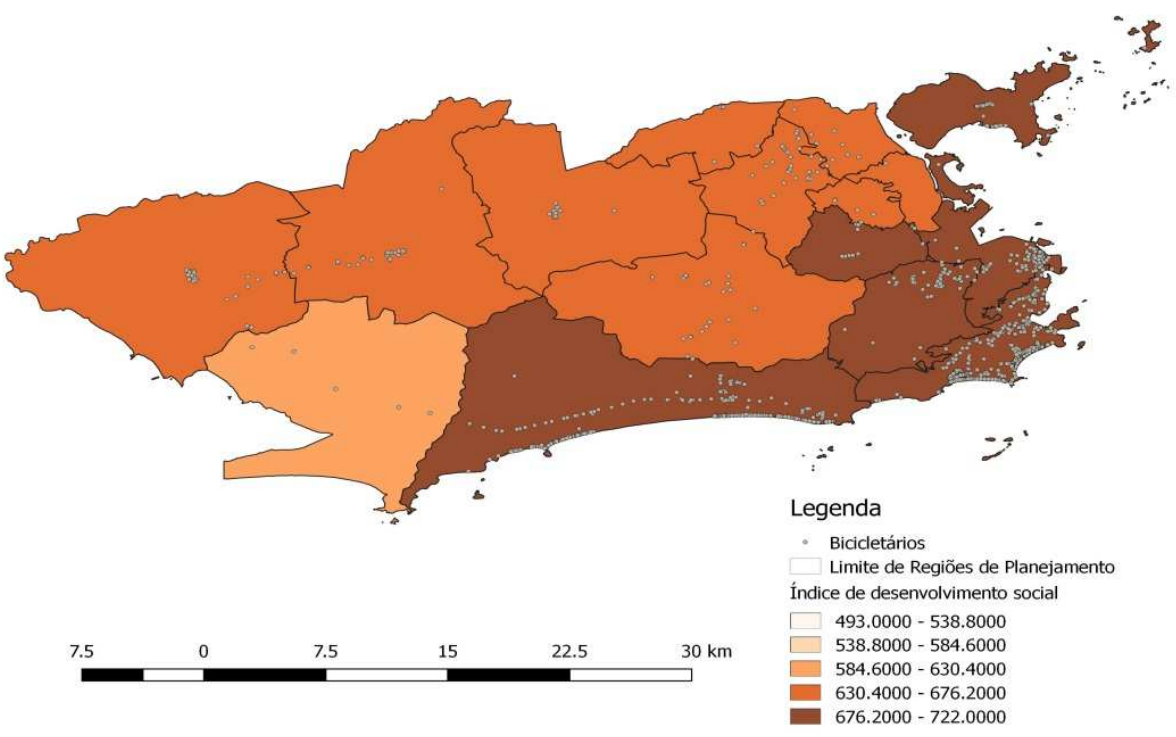

Mapa 5 - Bicicletários por regiões de planejamento do município do Rio de Janeiro e índice de desenvolvimento social.

Elaboração própria, 2017.

Os Mapas de Rede cicloviária, bicicletários e bicicletas compartilhadas demonstram a concentração desses serviços providos pela prefeitura no município. As bicicletas 
compartilhadas, populares em várias cidades do mundo, funcionam no Município do Rio de Janeiro como uma iniciativa público-privada que foi implantada no Rio de Janeiro em dezembro de 2008. Trata-se de estações compostas por bicicletas de aluguel, nas quais o indivíduo possuidor de cartão de crédito, telefone e identidade pode realizar o cadastro mensal, semanal ou diário, pagar uma determinada taxa e retirar a bicicleta da estação por uma hora, ao final dessa hora deve devolver em qualquer estação da cidade. Após 15 minutos da devolução pode retirar outra bicicleta, e assim por diante, sem custos extras. A rede cicloviária é composta por vias estritamente para bicicletas e vias compartilhadas com pedestres ou automóveis. Os bicicletários são estacionamentos de bicicletas em locais públicos, como praças, calçadas, estações de metrô ou trem etc.

Os mapas 4 e 5 utilizam o índice de desenvolvimento social que é uma medida comparativa usada para classificar determinadas áreas (bairros, áreas de planejamento urbano, estados, países etc) pelo seu grau de "desenvolvimento humano". Para a aferição do índice utilizado nesse respectivo mapa são utilizados 10 indicadores a partir do indicador de variáveis do Censo Demográfico (IBGE), subdivididas em grandes dimensões de análises, sendo elas: acesso ao saneamento básico, qualidade habitacional, grau de escolaridade e disponibilidade de renda. As variáveis escolhidas cobrem o aspecto sócio-urbanístico e trata-se de áreas cujo índice é mais elevado, identificadas por cores mais escuras, e que correspondem a áreas com maior qualidade de vida, sendo, geralmente, as mesmas áreas em que há concentração dos serviços de mobilidade urbana por bicicleta.

Os mapas demonstram a espacialização do serviço para a mobilidade urbana por bicicleta no Rio de Janeiro, a concentração desses serviços nas áreas nobres e a irregular presença nas demais áreas, principal objeto de pesquisa nesse trabalho. A seguir, um fragmento do artigo "A apropriação dos benefícios das ações do Estado em urbanas: seus determinantes e análise através de ecologia fatorial", de 1981, que, se provando atual, reforça o exposto previamente. Ademais, o texto acrescenta como a ação pontual e desigual do governo causa um círculo sem fim, prejudicando em longo prazo os cidadãos que não são beneficiados com essas ações, pois aprofunda a segregação sócio-espacial, o que pode contagiar as próximas intervenções do Estado, as quais, nesse trabalho, foram julgadas essenciais para a mobilidade da população. 
No presente trabalho mostramos a importância da apropriação dos benefícios líquidos das ações do Estado nas áreas urbanas em termos da distribuição da renda real. Nesta apropriação o espaço é uma variável importante no sentido de que as localizações determinam a área de impacto das ações do Governo, tais como no caso de investimentos ou no de fornecimento de serviços públicos. Este impacto influi sobre os níveis de preços que podem provocar mudanças na segregação residencial segundo grupos de rendimento, a qual, por sua vez, pode afetar as ações do Estado nos períodos subsequentes àquelas intervenções anteriores. (VETTER; PINTO; FREDRICH e MASSENA, 1981, p. 462)

O Estado, como provedor e administrador dos capitais investidos em mobilidade urbana, tem negado veemente aos cidadãos das áreas onde a população é maior, e o rendimento médio mensal é mais baixo, os serviços que proporcionariam mais rapidez para que essa se desloque até um meio de transporte de massa, como o trem ou o BRT, ou para otimizar o deslocamento dentro da própria área de planejamento ou bairro. Historicamente o Rio de Janeiro privilegiou as áreas nobres em detrimento das mais pobres, o que vem aprofundando a desigualdade social no município. A seguir, temos um trecho do artigo: Análise da relação entre o sistema de transporte e a exclusão social na cidade do Rio de Janeiro.

O problema da exclusão social nas metrópoles brasileiras está relacionado com o sistema de transporte. Esta relação pode ser observada nos baixíssimos níveis de mobilidade da população de baixa renda que detém metade ou menos da metade dos índices de mobilidade das classes de alta renda. (LEMOS D., SANTOS M., PORTUGAL L, 2004, p. 50)

Observando os gráficos, pode-se constatar que, na maioria das vezes, bons índices de acessibilidade e bons níveis de renda e de desenvolvimento humano correspondem a altos índices de investimentos em serviços para mobilidade por bicicleta, ou seja, altos índices de investimentos do dinheiro público para essa finalidade, demonstrando também a importância desse modal.

Por meio da análise da literatura acadêmica, cabe ressaltar a forte correlação entre mobilidade urbana e os níveis de renda da população. Nesse sentido, o presente estudo pretende reforçar que tal dinâmica social se dá na medida em que o nível da renda é proporcional ao nível da mobilidade da localidade. Isto é, os altos níveis de mobilidade por bicicleta acompanham a população com maior poder aquisitivo, residente em áreas captadoras de maior investimento público e privado. 
O que ocorre no Rio de Janeiro são medidas sucessivas e sistemáticas, as regiões atuais são formadas historicamente por políticas de governo que sempre beneficiavam umas áreas em detrimento de outras, deixando nítida uma absoluta contenção de mobilidade para a classe de renda baixa. Uma das estratégias de governo para o combate à exclusão social consiste na garantia do acesso aos serviços públicos e fundamentais, entre os quais ao transporte urbano, mas é visível que essa estratégia não esta sendo utilizada.

\section{Considerações finais}

A prefeitura do município do Rio de Janeiro, como Estado contido de ideologias, age no caso das bicicletas compartilhadas, investindo os recursos públicos de forma díspar, para a realização do projeto de um novo modal de mobilidade para o Rio de Janeiro. Opera sobre a organização e a escolha dos locais para serem alocadas as estações, as ciclovias, ciclofaixas e toda a rede cicloviária, através de estudos da própria secretária do governo, ou seja, o intuito governamental é assegurar a reprodução da desigualdade explícita nessas escolhas e já fortemente demarcada no município, aumentando, assim, a reprodução do capital, em detrimento de parte da população que encontra-se parcialmente excluída das políticas públicas.

Os mapas e planilhas reforçam o descrito nos texto, em que há uma espacialização desigual em relação aos investimentos públicos e privados no município do Rio de Janeiro, a qual teve seu processo de evolução urbana marcada pelo processo de desigualdade sócioeconômica, demostrando, assim, que a capital fluminense é uma em duas, um município onde os grupos sociais de alto status vivem e a área onde os grupos de baixo e médio status vivem, muitas vezes por falta de escolha, vide os altos valores do solo urbano em áreas onde o Estado se faz presente.

A localização da distribuição das ações do Estado dentro do perímetro urbano no Rio de Janeiro, relacionados ao modal de bicicletas, mostra-se desigual. Notando-se assim a importância do espaço, que é uma variável essencial, assim como a renda dos moradores desses bairros. Desse modo, entendemos que a espacialização dos suportes para bicicletas 
reproduz o modelo de cidade estratificada, onde o município dos ricos se contrapõe ao município dos pobres, e segue o círculo de segregação dos serviços públicos apontados por Mauricio de A. Abreu no século XX.

A mobilidade por bicicleta é uma nova realidade no Rio de Janeiro e no mundo. Como meio de transporte só traz benefícios para os cidadãos, agilidade nos percursos de curta e média distancia, melhora na qualidade do ar, na diminuição do sedentarismo que tanto afeta a população do Brasil e do mundo, ajuda na redução de risco de enfarto em $50 \%$, redução do peso, dentro outros. As cidades que investem em um sistema de transporte mais humano como a bicicleta, tornam seu espaço público realmente público, já que mais pessoas deixaram seus carros em casa para andar de bicicleta e ocupar o município. Diferente do transporte rodoviarista motorizado (o carro) que transforma cada vez mais os espaços públicos em apenas locais de passagem, fazendo com que os seres não se enxerguem nesses trajetos, cada um fica em sua caixa, cada vez mais distantes um dos outros, sem se apropriarem do espaço da cidade.

Neste sentido, o estudo dos investimentos públicos mostra-se fundamental e necessário para que seja entendida a construção do espaço das cidades e, assim, a espacialização dos diferentes grupos sociais e, deste modo, entender como o transporte e a espacialização desses grupos repercutem na vida social desse individuo. Tal estudo viabiliza uma intervenção, de forma a buscar investimentos nas áreas apontadas como estando em desvantagem e, dessa maneira, seja revertido o processo assimétrico de serviços público amplamente disseminado nas cidades brasileiras.

Tais medidas evitam, ainda, que se mantenha uma tolerância à injustiça social e uma manutenção de uma espécie de cinismo social, onde os direitos somente são garantidos para aqueles que têm um poder aquisitivo para dispor de recursos e assegurá-los, de acordo com Lemos, Santos e Portugal (2004, p. 50). Assim, não se pretende esgotar a discussão, porém levantar possibilidades de diálogo, diante das diferentes avaliações e apontar para uma maior consistência das reflexões e das sugestões para o setor. 


\section{Referências bibliográficas}

ABREU, Maurício de Almeida. A Evolução Urbana do Rio de Janeiro. $4^{\circ}$ edição. Rio de Janeiro: IPP, 2011. ISBN 9788587649072.

ALMEIDA, Antonio José Pereira; STROH, Paula Yone. A espacialização dos serviços sociais urbanos de saúde e educação em maceió. Encontro Nacional dos geógrafos, Crise práxis e autonomia: espaços de resistência e de esperanças espaço de diálogos e práticas. XVI. Porto alegre: 2010. Disponível em: < www.agb.org.br/evento/download.php?idTrabalho=3001> Acessado em julho de 2017. ISBN 978-85-9990702-3.

ANDRADE, Hanrrikson. Rio é a cidade onde moradores mais perdem tempo no trajeto casa-trabalho. NOTICIAS UOL. 11/09/2015. Disponível em: <https://noticias.uol.com.br/cotidiano/ultimas-noticias/2015/09/11/trajetocasa-trabalho-leva-ao-menos-duas-horas-em-oito-capitais-diz-firjan.htm> Acessado em: 6 de jun. de 2017.

ARMAZÉM DE DADOS, Estatísticas Municipais Transporte terrestre. 2011. Disponível em <http://www.armazemdedados.rio.rj.gov.br/> Acessado em 6 jun, 2017.

ARMAZEM DE DADOS, Mapa Digital do Rio de Janeiro - Ciclovias. Disponível em: <http://pcrj.maps.arcgis.com/apps/webappviewer/index.html?id=5005177263f44932b87564b4fb8defdc>

Acessado em 6 junho, 2017.

ANEXO TÉCNICO I: informações sobre todas as áreas de planejamento coordenação operacional de atendimento em emergências (emergência PRESENTE). Disponível em: <http://www.rio.ri.gov.br/dlstatic/10112/1529762/DLFE-220205.pdf/1.0> Acessado em 6 jun, 2017.

BONI, Melissa Passamani. Desigualdade sócio-espacial e distribuição dos recursos públicos na cidade de Vitória. Dissertação (Mestrado em Planejamento Regional e Gestão de Cidades) Universidade Candido Mendes Campus de Campos dos Goytacazes/RJ.2009.

BRASIL, diário oficial do município do Rio de Janeiro, comissão especial de licitação, cel/próprios errata ref.: concorrência, cel/próprios/cn-05/2013 processo : 04/550.508/201.avisos, editais e termos de contratos, secretaria da casa civil. Disponível em: <http://www.buscaoficial.com/c/diario/cGol8ndlu/>

BRASIL. Constituição da República Federativa do Brasil. Brasília, DF: Senado Federal: Centro Gráfico, 1988. 292 p. julho de 2017.

BRASIL. LEI COMPLEMENTAR № 111, DE 1o DE FEVEREIRO DE 2011, Dispõe sobre a Política Urbana e Ambiental do Município, institui o Plano Diretor no Rio de Janeiro e dá outras providências, Diário Oficial da república Federativa do Brasil. Rio de Janeiro, RJ, 1 fev. 2011 . Disponível em: <http://www.rio.rj.gov.br/dlstatic/10112/4600307/4117400/lei_compl_111.pdf> Acessado 6 de jun. de 2017.

CÁSSIA, Rita de. Políticas públicas no Nordeste do Brasil: a produção de enclaves e de desigualdades socioespaciais. (GOT), n.o 8, dez, 2015. Centro de Estudos de Geografia e Ordenamento do Território, p. 11-31. Disponível em: <dx.doi.org/10.17127/got/2015.8.002>.

COUTINHO, Maria Chalfin. Dialética da exclusão / inclusão em uma organização industrial. UFSC. Raeeletrônica, v. 5, n. 1, art. 7, jan./jun. 2006. São Paulo. ISSN 1676-5648

FILMES, Maria Farinha. Bikes vs Carros, São Paulo: Prefeitura de São Paulo e Banco Itaú.26/06/2015 Disponível em: <http://vadebike.org/2015/05/documentario-bikes-vs-cars-lancamento-exibicao-brasil/> Acessado em 10 de junho de 2017.

IBGE. Síntese de indicadores socais uma analise das condições de vida da população brasileira 2013. Disponível em: <http://biblioteca.ibge.gov.br/visualizacao/livros/liv66777.pdf> Acessado em 11 de julho de 2017.

LEFEBVRE, Henri. A Vida Cotidiana no Mundo Moderno. Volume 24. São Paulo: Ática, 1961. ISBN 8508037929

LEMOS, Diana Scabelo da Costa Pereira da Silva; SANTOS, Márcio Peixoto de Sequeira; PORTUGAL, Licínio da Silva. Análise da Relação entre o Sistema de Transporte e a Exclusão Social na Cidade do Rio de Janeiro. ENGEVISTA, v. 6, n. 3, p. 36-53, dez, 2004 .. 
NERI, Marcelo Cortes. Performance Social das 27 capitais brasileiras entre mandatos de prefeitos. 2009. Disponível

<http://www.cps.fgv.br/ibrecps/olimp/Olimp_Fgv_Cps_Ranking_por_Capitais_FORMATADO_PA2.pdf>

OLIVEIRA, Luís Roberto Cardoso de. Concepções de igualdade e cidadania. Contemporânea - Revista de Sociologia da UFSCar. São Carlos, Departamento e Programa de Pós-Graduação em Sociologia, 2011, n. 1, p. 35-48.

ORTIGOZA, Silvia Aparecida Guarnieri. Paisagens do consumo: São Paulo, Lisboa, Dubai e Seul. São Paulo: Cultura Acadêmica, 2010. (Coleção PROPG Digital - UNESP). Disponível em: <http://hdl.handle.net/11449/109158>. ISBN 9788579831287.

SILVA, André da. Mobilidade urbana e equidade social: possibilidades a partir das recentes políticas de transporte público na Metrópole do Rio de Janeiro. Revista de Geografia e Ordenamento do Território (GOT), n.o 10, dez, 2016. Centro de Estudos de Geografia e Ordenamento do Território, p. 293-317. Disponível em: $<$ dx.doi.org/10.17127/got/2016.10.014>.

TRANSPORTE ATIVO, Perfil Ciclista. Retrato de um Brasil que pedala. Ano 2015. Acessado julho de 2017. Disponível em: <http://transporteativo.org.br/ta/?tag=perfil-ciclista\&paged=2>

VETTER David Michael; PINTO, Dulce Maria Alcides; FREDRICH, Olga Buarque de Lima; MASSENA, Rosa Maria Ramalho. A proposição dos benefícios das ações do Estado em áreas urbanas: seus determinantes e análise através de ecologia fatorial. Ano 43, n. 04, out/dez, 1981. Rev. Bras. Geogr. 455-638. Rio de Janeiro.

PORTAL GEO. Indicadores ambientais da cidade do Rio de Janeiro. Disponível em: $<$ http://portalgeo.rio.rj.gov.br/protocolo/Indicadores_capitulos/[15-

IA_Part1_CaractCidade_CaractSociodemo_1-14].pdf>

PORTAL DA FIRJAN. O Custo dos Deslocamentos nas principais áreas urbanas do Brasil. Disponível em: $<$ http://www.firjan.com.br/publicacoes/publicacoes-de-economia/o-custo-dos-deslocamentos-nas-principaisareas-urbanas-do-brasil.htm\#pubAlign>. 